\title{
Solid + liquid equilibria and molecular structure studies of binary mixtures for nitrate ester's stabilizers: Measurement and modeling
}

\author{
Salim Chelouche ${ }^{a, *}$, Djalal Trache ${ }^{a, *}$, Catarina M.S.S. Neves ${ }^{\mathrm{b}}$, Simão P. Pinho ${ }^{c, d}$, \\ Kamel Khimeche ${ }^{\mathrm{a}}$, Mokhtar Benziane ${ }^{\mathrm{e}}$ \\ a UER Procédés Energétiques, Ecole Militaire Polytechnique, EMP, BP 17 Bordj-El-Bahri, Algiers, Algeria \\ ${ }^{\mathrm{b}}$ CICECO - Aveiro Institute of Materials, Department of Chemistry, University of Aveiro, 3810-193 Aveiro, Portugal \\ ' Associate Laboratory LSRE-LCM, Departamento de Tecnologia Química e Biológica, Instituto Politécnico de Bragança, Bragança, Portugal \\ d Centro de Investigação de Montanha (CIMO), Instituto Politécnico de Bragança, Campus de Santa Apolónia, 5300-253 Bragança, Portugal \\ ecole Supérieure du Matériel ESM, BP 188 Beau-Lieu, Algiers, Algeria
}

A R T I C L E I N F O

\section{Keywords:}

Propellant stabilizer

Eutectic mixture

Semi-empirical models

Excess thermodynamic properties

Physicochemical characterization

Microstructure

\begin{abstract}
A B S T R A C T
Solid-liquid equilibria (SLE) data for two binary organic mixtures of N-(2-methoxyethyl)-p-nitroaniline $+\mathrm{N}$ ethyl-4-nitroaniline (S1) and N-(2-ethanol)-p-nitroaniline + N-ethyl-4-nitroaniline (S2) have been measured using differential scanning calorimeter to build the corresponding solid-liquid phase diagrams. The quality of the SLE data has been checked by consistency tests, presenting good quality factors for both systems. Simple eutectic behavior has been observed for these systems with the presence of a solid-solid transition for S2. The SLE data have been correlated by means of Wilson, NRTL, and UNIQUAC equations. The used models calculate the equilibrium temperatures very satisfactorily. The best modeling results were obtained using the Wilson equation with a root mean square deviation between experimental and calculated values for S1 and S2 of 1.15 and 1.99 , respectively. The Wilson, NRTL, and UNIQUAC equations have also been used to compute excess thermodynamic functions viz. excess Gibbs energy, enthalpy, and entropy. The obtained results demonstrated a moderate positive deviation to ideality for S1, and a strong positive deviation for S2, unveiling the nature of the interactions between the compounds forming each mixture. In addition, microstructural studies have been carried out by FTIR, XRD and optical microscopy. Weak molecular interactions have been shown for the eutectic compositions. Jackson's roughness parameter was calculated and found to be greater than 2, suggesting the faceted morphology with irregular structures.
\end{abstract}

\section{Introduction}

Solid propellants are usually employed in military ammunition. To ensure a safe life and long storage time under adverse storage conditions with acceptable chemical, thermal, mechanical and ballistic performances, such materials should contain various chemical compounds such as stabilizers [1]. Solid propellants consisting of nitrocellulose (NC) and/or other nitrate esters (NE), are inherently chemically unstable and tend to decompose even at the normal storage conditions because of the low bonding energy $(155 \mathrm{~kJ} / \mathrm{mol})$ of the nitrate ester group $\left(\mathrm{CH}_{2}-\mathrm{O}-\mathrm{NO}_{2}\right)$ [2-4]. They undergo slow decomposition and generate nitrogen oxides $\left(\mathrm{NO}_{\mathrm{X}}\right)$ which react with the residual moisture present in the propellant and form nitrous and nitric acids. If nothing is done to inhibit this decomposition reaction, the products act as catalysts in the decomposition of the nitrate ester, and a further decomposition reaction channel is opened which is commonly named autocatalytic decomposition [5].

To deal with this natural slow thermal degradation, stabilizers are commonly added to the NE formulations. These substances are necessary to improve the shelf-life of propellants and to lower the risks associated with their decomposition during manufacture, storage, and use. Furthermore, the ballistic performance of propellant has been observed to change with its aging, due to physical changes in degraded propellant grains [6].

For a safe storage, stabilizers must have a relatively high melting temperature compared to that of storage. In fact, an energetic substance containing a stabilizer with a low melting point can cause its fusion. This could then cause the diffusion of the liquid within the energetic material, leading to a loss of stabilizing efficiency due to the decrease of stabilizers amount. Furthermore, the migration of the liquid after the fusion can lead to the loss of the energetic material structure integrity, thermal stability reduction, and decrease in the desired chemical,

\footnotetext{
* Corresponding author.

E-mail addresses: salim.chelouche@gmail.com (S. Chelouche), djalaltrache@gmail.com (D. Trache).
} 
mechanical and ballistic characteristics, which can lead to self-ignition or explosion.

A wide range of chemicals has been investigated as stabilizers in propellants. However, none of these proposed substances completely fill the requirements for a safe and effective stabilizer. The research in this area is very active, seeking stabilizers that are effective and presenting fewer potential negative environmental and health impacts.

The most widely employed stabilizers are from the classes of aromatic amines (e.g. diphenylamine) and urea derivatives (Akardite-II, Akardite-III, ethyl centralite, methyl centralite) [1,2]. Some emerging substances are also being studied and evaluated (polymers, ionic liquids, organic and inorganic materials, etc.), and adding some more complexity to the search for optimum propellant formulations, stabilizers can be used either singly or in mixtures.

Numerous research studies devoted to the stabilization of nitrate esters have been conducted without sufficiently elucidating the chemical reactions that can occur between the stabilizers in the energetic material [6-9], but less attention has been paid to their thermodynamic properties and structural details. In this context, within the last ten years, several studies have been carried out by our research group with conclusive and interesting results [3,10-12].

Organic eutectics may act as blend materials, and hence their investigation for possible use in the synthesis of energetic materials is important and should be done in detail. In this paper we perform phase equilibria and microstructure studies by means of differential scanning calorimetry (DSC), Fourier transform infrared (FTIR), x-ray diffraction (XRD) and optical microscopy, for two binary mixtures of organic stabilizer's, that is N-(2-methoxyethyl)-p-nitroaniline + N-ethyl-4-nitroaniline (S1) and N-(2-ethanol)-p-nitroaniline + N-ethyl-4-nitroaniline (S2), respectively. In particular, SLE data have been correlated by means of Wilson, NRTL and UNIQUAC equations, which were also employed to compute excess thermodynamic functions, helping to understand the kind of interaction between the constituents of both systems.

\section{Experimental and methods}

\subsection{Materials}

In this work, three chemical products have been used to prepare the two binary mixtures of stabilizers. Chemical structures of studied compounds are given in Fig. 1. N-(2-methoxyethyl)-p-nitroaniline (MENA) and N-(2-ethanol)-p-nitroaniline (ENA) were synthesized and purified following the method indicated by Gibson [13]. Their purities were checked by DSC and FTIR analysis and evaluated to be greater than 98(wt.\%). For the new synthesized compounds MENA and ENA, ${ }^{1} \mathrm{H}$ and ${ }^{13} \mathrm{C}$ NMR spectra are given as SM (Figs. S1-S4). The N-ethyl-4nitroaniline (NENA) was supplied by Sigma-Aldrich. Its mass purity was certified by the manufacturer to be greater than 99 (wt.\%) and has been used without further purification. Table 1 compiles the source and purity of the compounds.
Their melting temperatures and fusion enthalpies were measured by differential scanning calorimetry (DSC). Table 2 lists the obtained results and their comparison with the available literature data. The knowledge of these physicochemical properties is of great importance for the determination of the activity coefficients as well as for the thermodynamic modeling. Additionally, Table 2 presents also the experimental molar volumes $\left(\mathrm{V}_{\mathrm{M}}, \mathrm{cm}^{3} / \mathrm{mol}\right)$, which are calculated according to Eq. (1) [14]:

$V_{M}=\frac{M}{\rho}$

where $M$ is the mass molar $(\mathrm{g} / \mathrm{mol})$ of the pure compound and $\rho$ its density $\left(\mathrm{g} / \mathrm{cm}^{3}\right)$ measured at $298.15 \mathrm{~K}$.

\subsection{Apparatus and procedure}

Before carrying out the DSC experiments, a series of solid binary mixtures have been first prepared. Considerable caution has been paid in preparing the samples; each mixture is placed in a separate Pyrex glass test tube and kept airtightly. The solids are slowly mixed and heated up to a temperature about $15{ }^{\circ} \mathrm{C}$ above to the melting temperature of component presenting higher melting temperature. When the first droplets of liquid appear, rapid and continuous stirring is recommended in order to ensure a good homogeneity of the binary mixture. Then, instantaneous cooling in the nitrogen liquid is carried out, in order to solidify the mixture and to keep the same homogeneous structure of the binary mixture. The resultant solid was powdered in a clean agate mortar with a little pressure as possible and dried in desiccators. The rapid cooling of molten samples ensured a uniform steric concentration of components in the mixtures and homogeneity of the final molecular blend.

The thermal properties measurements were carried out by means of a Perkin-Elmer DSC8000 (PerkinElmer, Inc.,710 Bridgeport Avenue Shelton, CT 06484-4794, USA). DSC device was calibrated with high pure indium and confirmed by analysis with zinc. The precision is within $\pm 0.1 \mathrm{~K}$ and $\pm 2 \%$ for the temperature of fusion (onset of melting peak) and the enthalpy of fusion (integral over the melting peak), respectively.

A cleaning of the measuring equipment is done ahead by infusing with nitrogen gas and then heating to a temperature of $500{ }^{\circ} \mathrm{C}$. This procedure is carried out every time a new material series is going to be analyzed. For each measurement, 4-6 mg (Mettler H31 balance, precision $\pm 0.0002 \mathrm{~g}$ ) of the sample is charged to cramped aluminum crucibles, while an empty pan of the same type is employed as a reference.

The procedure for DSC measurements is similar to those implemented in our research group for analogous mixtures [3,10,11]. It guarantees the quality and precision of the data as different heating and cooling rates, or isothermal periods, resulted in similar thermograms, without the appearance of unexpected thermal phenomena. Each sample undergoes first a heating cycle in which it is heated to a temperature higher than that of the mixture's component presenting the higher melting temperature, at a heating rate of $10 \mathrm{~K} / \mathrm{min}$, and then<smiles>COCCNc1ccc([N+](=O)[O-])cc1</smiles>

(a)<smiles>CCNc1ccc([N+](=O)[O-])cc1</smiles>

(b)<smiles>O=[N+]([O-])c1ccc(NCCO)cc1</smiles>

(c)

Fig. 1. Chemical structure of the studied compounds: (a) N-(2-methoxyethyl)-p-nitroaniline (MENA); (b) N-ethyl-4-nitroaniline (NENA); (c) N-(2-ethanol)-p-nitroaniline (ENA). 
Table 1

Source, purification method and final mass fraction purity of the studied compounds.

\begin{tabular}{|c|c|c|c|c|c|}
\hline Chemical name & Source & $\begin{array}{l}\text { Initial mass fraction } \\
\text { purity }\end{array}$ & Purification method & $\begin{array}{l}\text { Final mass fraction } \\
\text { purity }\end{array}$ & Analysis method \\
\hline $\begin{array}{l}\mathrm{N} \text {-(2-methoxyethyl)-p-nitroaniline } \\
\quad \text { (MENA) }\end{array}$ & Synthesis in our lab & - & Filtration + Repeated crystallization & 0.98 & $\begin{array}{l}\text { NMR }^{\mathrm{a}} \\
\text { FTIR }^{\mathrm{b}} \\
\text { DSC }^{\mathrm{c}}\end{array}$ \\
\hline N-ethyl-4-nitroaniline (NENA) & Sigma-Aldrich & 0.99 & none & 0.99 & - \\
\hline N-(2-ethanol)-p-nitroaniline (ENA) & Synthesis in our lab & - & Filtration + Repeated crystallization & 0.98 & $\begin{array}{l}\text { NMR }^{\mathrm{a}} \\
\text { FTIR }^{\mathrm{b}} \\
\text { DSC }^{\mathrm{c}}\end{array}$ \\
\hline
\end{tabular}

a Nuclear Magnetic Resonance spectroscopy.

b Fourier transformed infrared.

c Differential scanning calorimeter.

Table 2

Physical properties of pure compounds: molar volume at density temperature $T_{\rho}=298.15 \mathrm{~K}\left(V^{298.15}\right)$, the melting temperature $\left(T_{\mathrm{m}}\right)$ and the enthalpy of melting $\left(\Delta H_{\mathrm{m}}\right)$ in the DSC experiments, at $\mathrm{p}=0.1 \mathrm{MPa}$.

\begin{tabular}{llll}
\hline Compound & $\begin{array}{l}V^{298.15}\left(\mathrm{~cm}^{3} /\right. \\
\mathrm{mol})\end{array}$ & $T_{\mathrm{m}}(\mathrm{K})$ & $\Delta H_{\mathrm{m}}(\mathrm{kJ} / \mathrm{mol})$ \\
& & & \\
\hline N-(2-methoxyethyl)-p- & $152.7^{*}$ & $358.9^{\mathrm{a},{ }^{*}}$ & $27.3^{*}$ \\
nitroaniline (MENA) & $154.1^{\mathrm{c}}$ & $356.15-359.15$ & $25.95[30]$ \\
& $151.4^{\mathrm{d}}$ & {$[13]$} & $24.35[31]$ \\
N-ethyl-4-nitroaniline (NENA) & $127.2^{*}$ & $367.3^{\mathrm{a},{ }^{*}}$ & $22.7^{*}$ \\
& $130.9^{\mathrm{c}}$ & $367.15-368.15$ & $22.7[11]$ \\
& $125.7^{\mathrm{d}}$ & {$[29]$} & $22.76[30]$ \\
N-(2-ethanol)-p-nitroaniline & $137.5^{*}$ & $368.21^{\mathrm{b}}[11]$ & $19.21[31]$ \\
(ENA) & $138.6^{\mathrm{c}}$ & $381.0^{\mathrm{a},{ }^{*}}$ & $26.5^{*}$ \\
& & $380.65-383.15$ & $29.45[30]$ \\
& & {$[13]$} & $25.65[31]$ \\
\hline
\end{tabular}

Standard uncertainties u are $u(V)= \pm 0.4 \mathrm{~cm}^{3} / \mathrm{mol}, u\left(T_{\mathrm{m}}\right)= \pm 0.4 \mathrm{~K}, u\left(\Delta H_{\mathrm{m}}\right)$ $= \pm 0.7 \mathrm{~kJ} / \mathrm{mol}, u\left(T_{\rho}\right)= \pm 0.07 \mathrm{~K}, u_{r}(p)=0.05$.

* This work.

a Onset temperature.

b Peak top temperature.

c Girolami's method [32].

d Imerizi's method [32].

maintained at that temperature for $20 \mathrm{~min}$, before being cooled to $298.15 \mathrm{~K}$ at a cooling rate of $10 \mathrm{~K} / \mathrm{min}$. At the end of this treatment, the sample is maintained at $298.15 \mathrm{~K}$ for $20 \mathrm{~min}$. After a second heating is performed in a nitrogen atmosphere $\left(20 \mathrm{~cm}^{3} / \mathrm{min}\right)$ in the temperature range $313-390 \mathrm{~K}$ for the first system MENA(1)+NENA(2) and $323-400 \mathrm{~K}$ for the second ENA(1) + NENA(2), at a heating rate of $2 \mathrm{~K} /$ min. This scanning rate is low enough to approach the equilibrium measurement conditions and to increase the accuracy of the enthalpy of fusion calculations. Any further attempt to use a slower heating rate does not influence the quality and the precision of the measured data.

The determination of the enthalpies and temperatures of melting and the processing of the thermograms were done with Perkin-Elmer's Pyris software (PerkinElmer Life and Analytical Science, Chalfont Road, Seer Green, Buckinghamshire, HP9 2FX, UK). Measurement uncertainties were estimated to be \pm 0.0005 for the mole fraction, $\pm 0.4 \mathrm{~K}$ for the temperature and did not exceed $\pm 0.7 \mathrm{~kJ} /$ mol for the enthalpy of fusion.

For pure compounds, melting temperatures are obtained from the extrapolated onset temperature of the heat flow curves. This approach is followed by several authors [15-17] and can be explained by the fact that this point is independent of the sample mass. However, there are no such recommendations, about which temperatures to be used for binary mixtures. On the other hand, solidus (or eutectics) corresponds to the formation of a first liquid droplet in equilibrium with a bulk solid phase; hence, onset temperatures are used as eutectic temperatures, as it was applied by the vast majority of the authors [16-21]. At the same time, liquidus is defined as the disappearance of the last crystals in the
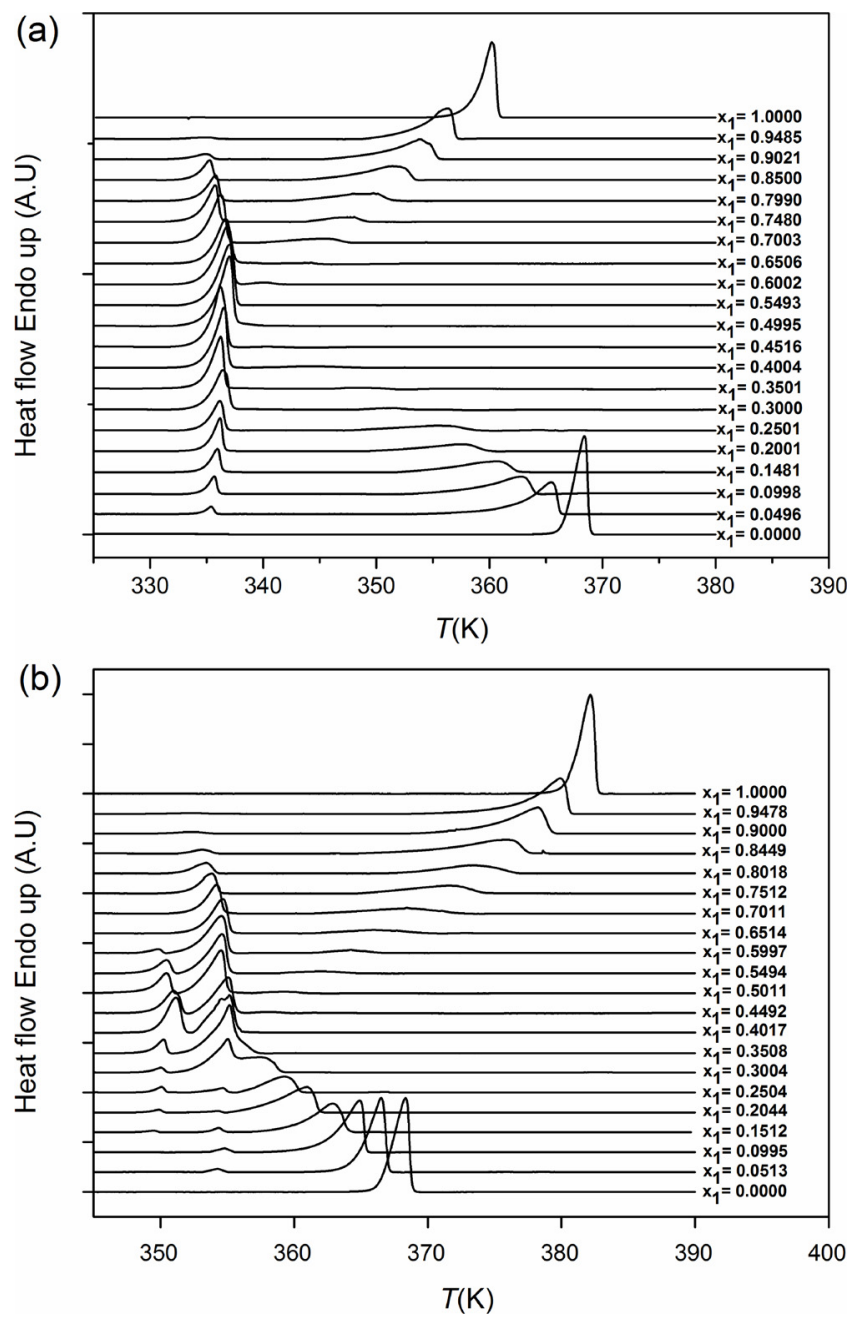

Fig. 2. DSC thermograms of (a) S1(MENA(1) + NENA(2)), (b) S2 (ENA(1) $+\operatorname{NENA}(2))$

liquid phase, and thus onset temperatures are probably not the best choice. The determination of the liquidus temperatures is not obvious. In fact, some studies identified $\mathrm{T}_{\text {liquidus }}$ from the onset temperature despite the qualitatively different nature of melting in a mixture to that in a pure substance [21]. Other studies have identified $T_{\text {liquidus }}$ as the peak top temperature $[22,23]$. However, it has been shown that this former represents the point where the energy exchange between the sample and thermocouples is at a maximum and does not correspond to the point of complete dissolution [21,24]. Some other studies have adopted numerical procedures applying post-experiments that take into account factors influencing the shape of the thermogram to identify 
Table 3

Experimental solid-liquid equilibrium data for MENA (1) + NENA (2) system at different MENA mole fractions $\left(x_{1}\right)$ and $\mathrm{p}=0.1 \mathrm{MPa}$ : the liquidus temperature $(T)$, the eutectic temperature $\left(T_{\mathrm{E}}\right)$, the melting enthalpy of the mixture $\left(\Delta H_{\mathrm{m}}\right)$, the melting enthalpy at the eutectic $\left(\Delta H_{\mathrm{E}}\right)$.

\begin{tabular}{llllll}
\hline$x_{1}$ & $T(\mathrm{~K})$ & $T_{\mathrm{E}}(\mathrm{K})$ & $\Delta H_{\mathrm{m}}(\mathrm{J} / \mathrm{g})$ & $\Delta H_{\mathrm{E}}(\mathrm{J} / \mathrm{g})$ & Solid phase \\
\hline 0.0000 & 367.3 & - & 136.6 & 0.0 & NENA (cr) \\
0.0496 & 366.0 & 334.5 & 115.0 & 7.6 & NENA (cr) \\
0.0998 & 363.8 & 334.7 & 100.6 & 17.7 & NENA (cr) \\
0.1481 & 362.2 & 334.7 & 87.7 & 30.8 & NENA (cr) \\
0.2001 & 359.7 & 335.0 & 75.6 & 43.0 & NENA (cr) \\
0.2501 & 357.8 & 334.9 & 64.2 & 50.2 & NENA (cr) \\
0.3000 & 354.4 & 335.0 & 53.5 & 68.7 & NENA (cr) \\
0.3501 & 351.7 & 334.7 & 48.4 & 82.7 & NENA (cr) \\
0.4004 & 348.1 & 334.8 & 34.6 & 93.0 & NENA (cr) \\
0.4516 & 342.5 & 334.8 & 19.9 & 104.5 & NENA (cr) \\
0.4995 & 339.4 & 334.9 & 7.7 & 114.4 & NENA (cr) \\
0.5493 & 337.4 & 335.0 & 2.9 & 121.0 & MENA (cr) \\
0.6002 & 341.5 & 334.9 & 18.0 & 102.6 & MENA (cr) \\
0.6506 & 344.8 & 334.8 & 31.0 & 85.6 & MENA (cr) \\
0.7003 & 347.4 & 334.7 & 45.4 & 69.3 & MENA (cr) \\
0.7480 & 348.8 & 334.3 & 65.8 & 56.5 & MENA (cr) \\
0.7990 & 351.2 & 334.2 & 85.9 & 41.6 & MENA (cr) \\
0.8500 & 353.2 & 333.9 & 99.6 & 26.0 & MENA (cr) \\
0.9021 & 355.1 & 333.4 & 111.0 & 12.2 & MENA (cr) \\
0.9485 & 356.9 & 333.5 & 125.0 & 6.3 & MENA (cr) \\
1.0000 & 358.9 & - & 139.1 & 0.0 & MENA (cr) \\
\hline
\end{tabular}

Standard uncertainties $u$ are $u(x)= \pm 0.0005, u(T)= \pm 0.4 \mathrm{~K}, u\left(\Delta H_{\mathrm{m}}\right)$ $= \pm 3.6 \mathrm{~J} / \mathrm{g}, u_{r}(p)=0.05$.

\section{Table 4}

Experimental solid-liquid equilibrium data for ENA (1) + NENA (2) system at different ENA mole fractions $\left(x_{1}\right)$ and $\mathrm{p}=0.1 \mathrm{MPa}$ : the liquidus temperature $(T)$, the eutectic temperature $\left(T_{\mathrm{E}}\right)$, the solid-solid transition temperature $\left(T_{\text {trans }}\right.$ $\mathrm{s}$-s), the melting enthalpy of the mixture $\left(\Delta H_{\mathrm{m}}\right)$, the melting enthalpy at the eutectic $\left(\Delta H_{\mathrm{E}}\right)$.

\begin{tabular}{lllllll}
\hline$x_{1}$ & $T(\mathrm{~K})$ & $T_{\mathrm{E}}(\mathrm{K})$ & $T_{\text {trans s-s }}(\mathrm{K})$ & $\Delta H_{\mathrm{m}}(\mathrm{J} / \mathrm{g})$ & $\Delta H_{\mathrm{E}}(\mathrm{J} / \mathrm{g})$ & Solid phase \\
\hline 0.0000 & 367.3 & - & - & 136.6 & 0.0 & NENA (cr) \\
0.0513 & 366.8 & 353.4 & - & 118.4 & 9.6 & NENA (cr) \\
0.0995 & 365.4 & 353.9 & 348.7 & 97.4 & 15.4 & NENA (cr) \\
0.1512 & 364.1 & 353.5 & 348.9 & 76.1 & 28.2 & NENA (cr) \\
0.2044 & 361.6 & 353.4 & 348.9 & 57.7 & 40.2 & NENA (cr) \\
0.2504 & 360.2 & 353.5 & 349.3 & 42.0 & 50.5 & NENA (cr) \\
0.3004 & 358.7 & 353.3 & 349.2 & 23.4 & 74.1 & NENA (cr) \\
0.3508 & 357.1 & 353.2 & 349.2 & 8.9 & 85.9 & NENA (cr) \\
0.4017 & 355.4 & 353.3 & 349.8 & 2.1 & 93.3 & ENA (cr) \\
0.4492 & 358.8 & 353.1 & 349.5 & 5.5 & 86.9 & ENA (cr) \\
0.5011 & 360.8 & 352.7 & 349.1 & 9.4 & 77.4 & ENA (cr) \\
0.5494 & 363.4 & 352.7 & 349.1 & 15.3 & 70.7 & ENA (cr) \\
0.5997 & 366.0 & 352.4 & 348.9 & 21.2 & 61.9 & ENA (cr) \\
0.6514 & 369.5 & 353.0 & 349.3 & 24.6 & 52.0 & ENA (cr) \\
0.7011 & 371.9 & 352.9 & 349.2 & 34.9 & 43.3 & ENA (cr) \\
0.7512 & 373.6 & 352.6 & - & 44.1 & 35.8 & ENA (cr) \\
0.8018 & 375.7 & 351.8 & - & 55.6 & 28.0 & ENA (cr) \\
0.8449 & 377.4 & 351.6 & - & 71.7 & 18.6 & ENA (cr) \\
0.9000 & 379.2 & 351.1 & - & 86.0 & 14.0 & ENA (cr) \\
0.9478 & 380.3 & 351.4 & - & 114.6 & 5.4 & ENA (cr) \\
1.000 & 381.0 & - & - & 145.5 & 0.0 & ENA (cr) \\
\hline
\end{tabular}

Standard uncertainties $u$ are $u(x)= \pm 0.0005, u(T)= \pm 0.4 \mathrm{~K}, u\left(\Delta H_{\mathrm{m}}\right)$ $= \pm 3.6 \mathrm{~J} / \mathrm{g}, u_{r}(p)=0.05$.

$T_{\text {liquidus }}$ from the data $[25,26]$. Still that these methods are limited by several factors [21].

In their recent work, Oakley et al. [21] reported the use of the endset temperature, without reference to any numerical model, as a robust and straightforward means of identifying $T_{\text {liquidus }}$ in hydrocarbon mixtures which results in a consistent liquidus temperatures data. Furthermore, other studies, that have adopted this approach, considered that the use of a slow enough scan rate results in a good approximation $[27,28]$. This approach is kept for the determination of the
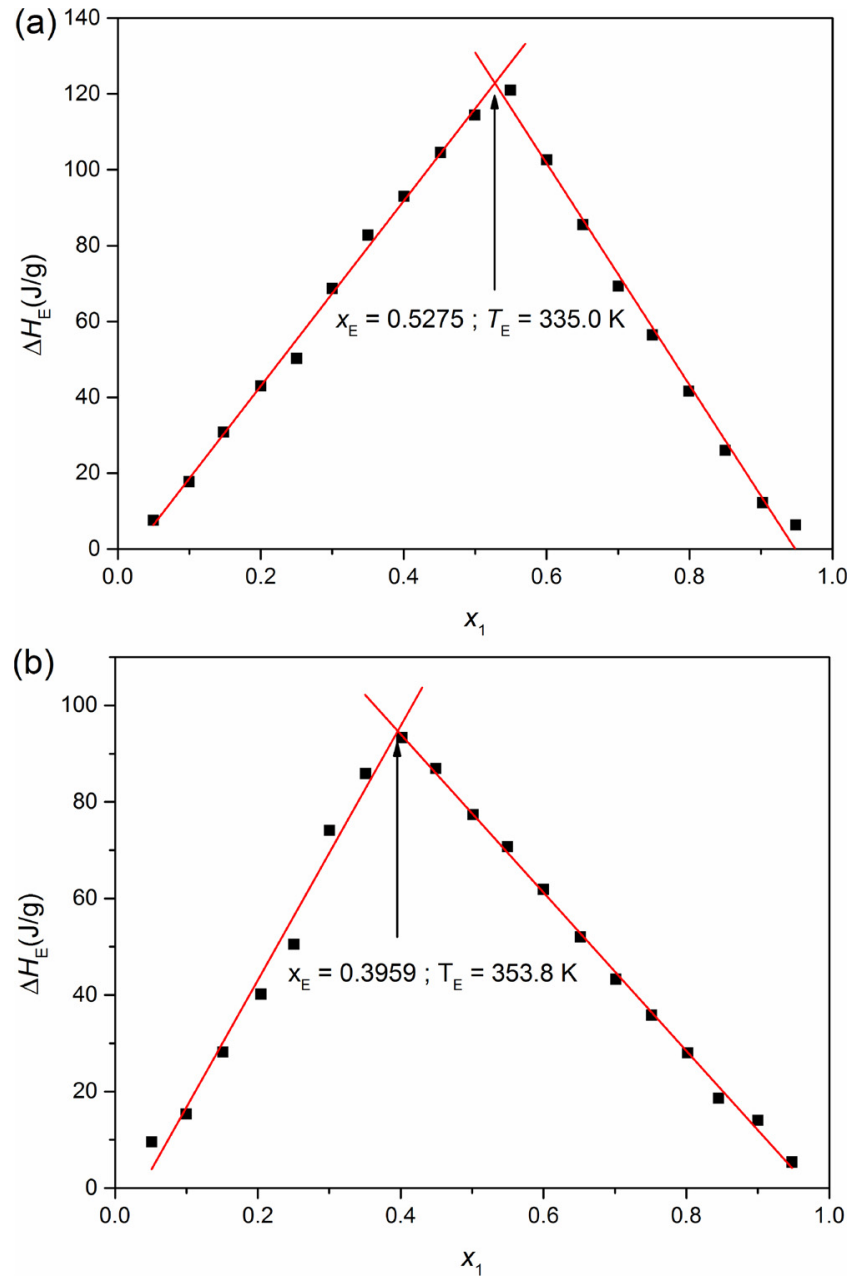

Fig. 3. Tamman plot of the studied binary systems (a) MENA + NENA, (b) ENA + NENA.

liquidus temperatures in the case of our organic binary mixtures.

The onset temperature is determined from the intersection between the tangent to the maximum rising slope upon melting, and the sample baseline curve measured prior to any melting whereas the endset temperature is determined in the same way, but in the opposite direction (the right part of the thermogram).

Components densities were measured using a Helium gas pycnometer (Micromeritics, AccuPyc II 1340, Georgia, USA). The volume of the three components is measured by replacing their void space with helium. The density is determined by independent and simultaneous measurements of the mass. The measurements were made three times, where each one consisted of 10 measurement cycles, providing 10 data points. Measurement uncertainties for all the components were estimated to be less than $\pm 0.003 \mathrm{~g} / \mathrm{cm}^{3}$ whereas the uncertainty associated with the temperature of the density experiments was evaluated to be less than $0.07 \mathrm{~K}$.

For FTIR Analysis, samples were embedded in $\mathrm{KBr}$ pellets and analyzed by using a Shimadzu spectrometer 8400 S. The spectra were recorded in transmittance mode in the range of $4000-600 \mathrm{~cm}^{-1} .64$ scans were co-added to achieve an acceptable signal-to-noise ratio. In all measurements, spectra resolution was maintained at $4 \mathrm{~cm}^{-1}$.

XRD analysis was carried out using a PANanyticalX'Pert Pro MultiPurpose Diffractometer with $\mathrm{Cu}$ Ka radiation. An X'Celerator detector was used to collect data over an angular range of $10-30^{\circ} / 2 \theta$, with a step size of $0.0170 / 2 \theta$ and a count time of 50.1650 s at each step. The voltage was chosen to be $45 \mathrm{kV}$ with a current of $40 \mathrm{~mA}$. Powdered specimens were prepared for X-ray diffraction analysis using the 
Table 5

Comparison between the experimental coordinates for the eutectic temperature $\left(T_{\mathrm{E}}\right)$ and the mole fraction $\left(x_{1, \mathrm{E}}\right)$ with calculated values.

\begin{tabular}{llllll}
\hline \multirow{2}{*}{ System } & \multicolumn{2}{l}{$T_{\mathrm{E}}(\mathrm{K})$} & & & \multicolumn{2}{l}{$x_{1, \mathrm{E}}$} \\
\cline { 2 - 3 } \cline { 5 - 6 } & Exp. & Cal. & & Exp. & \multicolumn{1}{l}{ Cal. } \\
\hline MENA (1) + NENA (2) & $335.0^{\mathrm{a}}$ & $335.5^{\mathrm{c}}$ & $0.5275^{\mathrm{b}}$ & $0.5412^{\mathrm{c}}$ \\
& & $337.1^{\mathrm{d}}$ & & $0.5480^{\mathrm{d}}$ \\
& & $337.8^{\mathrm{e}}$ & & $0.5486^{\mathrm{e}}$ \\
ENA (1) + NENA (2) & $353.8^{\mathrm{a}}$ & $334.7^{\mathrm{f}}$ & & $0.5156^{\mathrm{f}}$ \\
& & $356.5^{\mathrm{c}}$ & & $0.3959^{\mathrm{b}}$ & $0.3676^{\mathrm{c}}$ \\
& & $356.5^{\mathrm{d}}$ & & $0.3825^{\mathrm{d}}$ \\
& & $355.7^{\mathrm{e}}$ & & $0.3693^{\mathrm{e}}$ \\
& & $343.6^{\mathrm{f}}$ & & $0.4017^{\mathrm{f}}$
\end{tabular}

\footnotetext{
a Experimental eutectic temperature uncertainty $u\left(T_{\mathrm{E}}\right)= \pm 0.4 \mathrm{~K}$.

b Calculated eutectic molar fraction uncertainty $u\left(x_{\mathrm{E}}\right)= \pm 0.0156$.

c Calculated by Wilson.

d Calculated by NRTL.

e Calculated by UNIQUAC.

f Calculated by Ideal model.
}

PANaltiycal powder sample preparation Kit and back-loaded into nickel-coated steel sample holders. FTIR and XRD analysis were carried out at ambient temperature.

The microstructure characterization of the pure components and their eutectic compositions has been performed using an optical microscope type "Leica DM $2500 \mathrm{M}$ ". The samples were analyzed with the magnifications of 5, 10, 20 and 50 times. The stabilizers are placed on glass slides in small quantities and then heated until melting. The recrystallization is carried out at ambient temperature.

\section{Results and discussion}

\subsection{Solid-Liquid equilibria}

\subsubsection{Solid-liquid phase diagrams}

DSC thermograms for the two binary systems MENA(1) + NENA(2) and ENA(1) + NENA(2) are presented, respectively, in Fig. 2, while Tables 3 and 4 provide the experimental results for both systems.

Thermograms of pure components exhibit only an endothermic effect, corresponding to the melting phenomenon. A good agreement with literature data has been observed concerning the melting temperature of pure compounds [13,29]. For the melting enthalpy and molar volume no experimental data was possible to find, except for NENA, and instead estimating methods were applied [30-32], showing satisfactory coherence with the values measured in this work.

In the binary mixtures S1 and S2, two melting DSC peaks were observed. The first one was assigned to the melting of the eutectic while the second, registered at a higher temperature, was attributed to the liquidus line. In addition to those two peaks, a third one was observed in the case of the second binary mixture S2. This transition does not appear in the pure compounds (ENA or NENA) but can be seen for some mixture fractions at a constant temperature, lower than that of the eutectic. It is the result of a solid-solid transition, which occurs for fractions of ENA ranging from 0.1 to $0.7 \mathrm{~mol}$ fraction. The observed solid-solid transition may be interpreted as the decomposition of an intermediate solid below the eutectic, such as a peritectoid reaction [33].

The eutectic temperature is observed for each system, at a constant value, unlike that of the mixture melting point, which changes with the composition, so the two systems studied by DSC exhibit a simple eutectic behavior with complete miscibility in the liquid phase and immiscibility in the solid phase.

From the well-known Tamman's plot, and the linear regression of the eutectic enthalpy of melting versus the mole fraction [34] (Fig. 3(a) and (b)), the eutectic compositions of the MENA(1) + NENA(2) and ENA(1) + NENA(2) systems were determined as: $x_{1, \mathrm{E}}=0.5275$ and $x_{1, \mathrm{E}}=0.3959$, respectively. The uncertainty associated with the estimated eutectic molar fraction is evaluated to be less than \pm 0.0156 .

In order to accurately determine the eutectic temperatures, the two eutectics have been prepared based on their respective molar fraction defined from Tamman plot and then analyzed by DSC under similar conditions as mentioned above. As can be observed in plots (a) and (b) in Fig. S5 of the Supplementary materials, the thermogram corresponding to the first eutectic only presents one endothermic peak (eutectic melting) whereas that of the second system show two endothermic peaks (solid-solid transition and eutectic fusion respectively). The eutectic melting temperature measured for both S1 and S2 are found to be equal to $335.0 \mathrm{~K}$ and $353.8 \mathrm{~K}$, respectively. Likewise, the experimental enthalpies of melting of the two eutectics are evaluated to be equal to $22.3 \mathrm{~kJ} / \mathrm{mol}$ and $16.3 \mathrm{~kJ} / \mathrm{mol}$, respectively.

The eutectics coordinates are summarized in Table 5 . However, the uncertainties associated with each experimental eutectic temperature, molar fraction and melting enthalpy are found to be equal to the experimental errors associated to the measured samples given above.

The melting temperature of stabilizers intended to be introduced in energetic materials formulations must be high enough to prevent stability issues [1]. From the solid-liquid equilibria investigation, the two studied systems have relatively high eutectic temperatures compared to the ambient temperature. Therefore, theses eutectics can be safely incorporated into nitrate ester based-energetic materials formulations.

\subsubsection{Consistency tests}

Consistency tests for all type of phase equilibria were proposed by Kang et al [35]. The procedures proposed are essential for the validation of the experimental data and the development of high quality prediction and correlation models. Solid-liquid equilibrium experimental data of the two binary mixtures, together with relevant properties of pure compounds are used to verify the consistency of the data measured in this work. A quality factor $Q_{S L E}$ ranging between 0 and 1 is computed based on the differences between the melting temperature and enthalpy estimated from binary solubility data and the pure

Table 6

Quality factors values for the studied systems.

\begin{tabular}{|c|c|c|c|c|c|c|c|}
\hline MENA + NENA & Exp. (pure) & From SLE & $\Delta$ & \multicolumn{2}{|c|}{ Quality factors } & & $Q_{\text {SLE }}$ \\
\hline Tf1/K & 358.9 & 358.8 & 0.1 & $\mathrm{~F} 1$ & 1 & *0.25 & 0.928 \\
\hline Tf2/K & 367.3 & 367.8 & 0.5 & F2 & 1 & $* 0.25$ & \\
\hline Slope 1 & 0.0255 & 0.0262 & 0.027 & F3 & 1 & $* 0.25$ & \\
\hline Slope 2 & 0.0203 & 0.0260 & 0.280 & F4 & 0.714 & *0.25 & \\
\hline ENA + NENA & Exp. (pure) & From SLE & $\Delta$ & \multicolumn{2}{|c|}{ Quality factors } & & $Q_{\text {SLE }}$ \\
\hline $\mathrm{Tf} 1 / \mathrm{K}$ & 381.1 & 381.4 & 0.3 & $\mathrm{~F} 1$ & 1 & $* 0.25$ & 0.654 \\
\hline $\mathrm{Tf} 2 / \mathrm{K}$ & 367.3 & 367.8 & 0.5 & F2 & 1 & $* 0.25$ & \\
\hline Slope 1 & 0.0220 & 0.0358 & 0.627 & F3 & 0.319 & $* 0.25$ & \\
\hline Slope 2 & 0.0203 & 0.0341 & 0.679 & F4 & 0.295 & $* 0.25$ & \\
\hline
\end{tabular}


Table 7

Correlation of the (solid + liquid) data of the two binary mixtures by means of Wilson, NRTL and UNIQUAC equations: values of parameters and deviations.

\begin{tabular}{|c|c|c|c|c|c|c|c|c|c|c|}
\hline \multirow[t]{2}{*}{ System } & \multicolumn{6}{|c|}{ Parameters $(\mathrm{J} / \mathrm{mol})$} & \multicolumn{4}{|c|}{ Deviation $\sigma^{\mathrm{a}}(\mathrm{K})$} \\
\hline & $\begin{array}{l}\text { Wilson } \\
\Lambda_{12^{-}} \Lambda_{11}\end{array}$ & $\begin{array}{l}\text { Wilson } \\
\Lambda_{21}-\Lambda_{22}\end{array}$ & $\begin{array}{l}\text { NRTL } \\
\mathrm{g}_{12}-\mathrm{g}_{11}\end{array}$ & $\begin{array}{l}\text { NRTL } \\
\mathrm{g}_{21-} \mathrm{g}_{22}\end{array}$ & $\begin{array}{l}\text { UNIQUAC } \\
\mu_{12}\end{array}$ & $\begin{array}{l}\text { UNIQUAC } \\
\mu_{21}\end{array}$ & Wilson & NRTL & UNIQUAC & Ideal \\
\hline $\operatorname{MENA}(1)+\operatorname{NENA}(2)$ & 6901.27 & -2107.67 & -2571.40 & 5002.98 & 179.478 & 117.399 & 1.15 & 1.25 & 1.36 & 2.38 \\
\hline $\operatorname{ENA}(1)+\operatorname{NENA}(2)$ & 4081.24 & 1073.75 & -222.579 & 5135.80 & 656.685 & 533.759 & 1.99 & 2.23 & 2.35 & 6.69 \\
\hline
\end{tabular}

a According to Eq. (5).
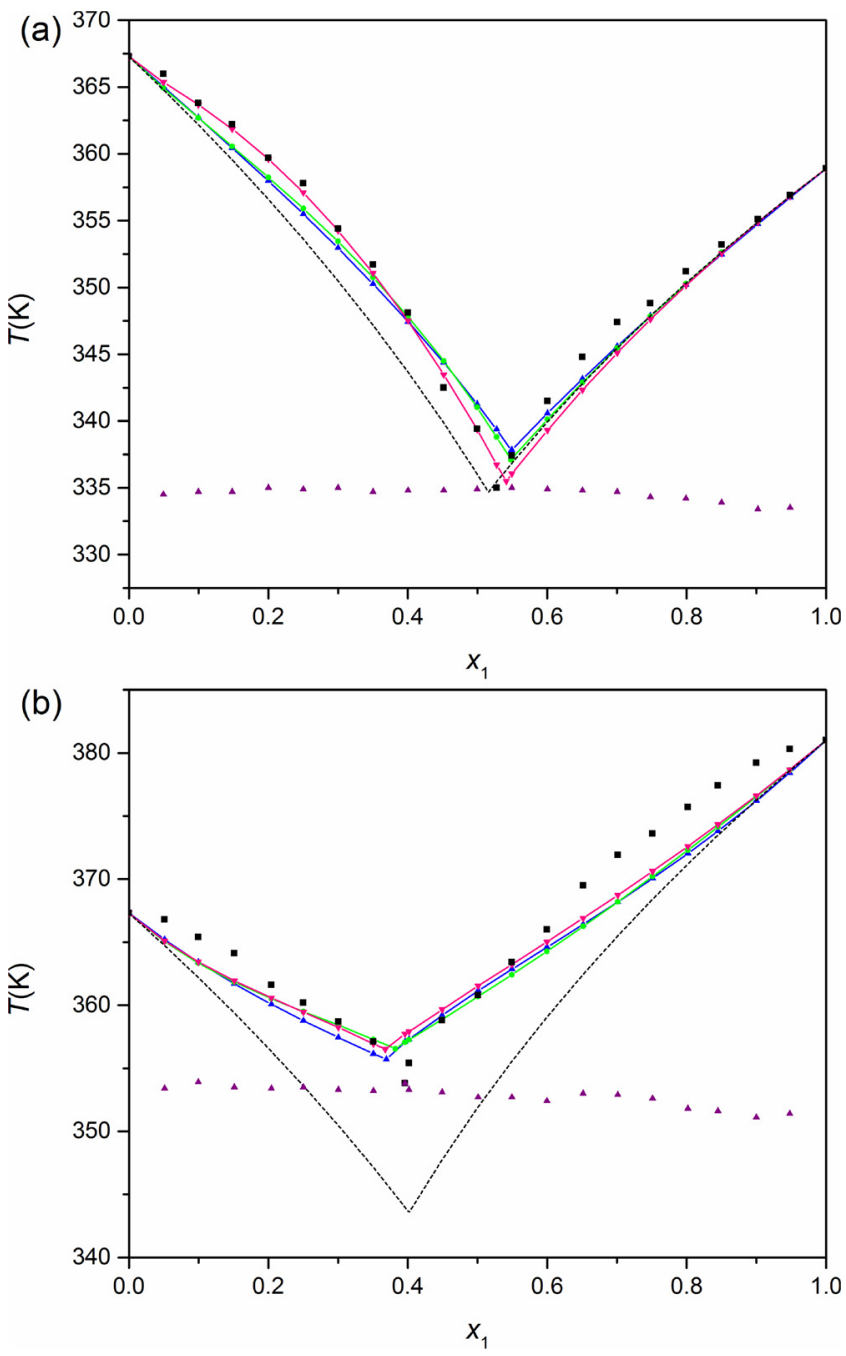

Fig. 4. Experimental and predicted SLE phase diagrams of (a)MENA (1) +


NRTL ; (৯) UNIQUAC ; (- - -) Ideal.

component property values. The detailed procedure can be found in the work by Kang et al. [35]. The obtained results for $Q_{S L E}$ are reported in Table 6, where the good quality of the measured data is confirmed since the global quality factors are 0.928 and 0.654 for S1 and S2, respectively. The divergence on the melting enthalpy remains the most significant component contributing to the decrease of the quality factor of the second system.

\subsubsection{Application of semi-empirical models}

For the two studied systems, the components are not miscible in the solid phase and completely miscible in the liquid phase. Therefore the activity coefficient $\left(\gamma_{1}\right)$ of the component, in the liquid phase, can be calculated according to Eq. (2) [3,10,36]: $\ln x_{1} \gamma_{1}=-\frac{\Delta_{\mathrm{m}} H_{1}}{R}\left(\frac{1}{T}-\frac{1}{T_{\mathrm{m}, 1}}\right)+\frac{\Delta_{\mathrm{m}} C_{\mathrm{p}, 1}}{R}\left(\frac{T_{\mathrm{m}, 1}-T}{T}+\ln \frac{T}{T_{\mathrm{m}, 1}}\right)$

where $x_{1}, \Delta_{\mathrm{m}} H_{1}, \Delta_{\mathrm{m}} C_{\mathrm{p}, 1}$ and $T_{\mathrm{m}, 1}$ stand, respectively, for the mole fraction, the enthalpy of melting, the difference in the heat capacity between liquid and solid states at the melting temperature, and melting temperature of pure solute $1, T$ is equilibrium temperature of the binary system and $R$ is the universal gas constant. As suggested by Prausnitz et al. [37], the first term on the right hand side of Eq. (2) is dominant. The heat capacity term is generally small enough and not known, and then is usually neglected when compared to the other terms. Since of the unavailability of $\mathrm{Cp}$ values of the pure components in both liquid and solid states, some tests were performed. In fact, testing different values for the heat capacity change of NENA, which presents the lower fusion entropy among the pure compounds studied, even when this value is as high as $50 \mathrm{~J} / \mathrm{mol} . \mathrm{K}$, the importance of the second term in the right side of Eq. (2) is always lower than $3.7 \%$, guaranteeing the validity of the simplification.

The deviation from ideal behavior and the type of interactions governing the systems can be better explained by means of excess thermodynamic functions, namely excess Gibbs energy $\left(G^{\mathrm{E}}\right)$, enthalpy $\left(H^{\mathrm{E}}\right)$, and entropy $\left(S^{\mathrm{E}}\right)$ [38-40]. These functions give a more quantitative idea about the nature of molecular interactions and are expressed as the difference between the thermodynamic functions of a real system and the ideal one at the same temperature and pressure. In this study, three methods based on the local compositions theory [37] were used to calculate the solute activity coefficients and to correlate the SLE data: Wilson, the NRTL, and the UNIQUAC models.

The unknown parameters of models were found by minimizing the objective function $\mathrm{F}_{0}$ using simplex method [41]:

$\mathrm{F}_{0}=\sum_{\mathrm{i}=0}^{\mathrm{n}}\left\{T_{\mathrm{i}}^{\text {exp }}-T_{\mathrm{i}}^{\mathrm{cal}}\left(x_{1 \mathrm{i}}, \mathrm{A}_{1}, \mathrm{~A}_{2}\right)\right\}^{2}$

where $\mathrm{n}$ is the number of experimental points, $T_{\mathrm{i}}^{\text {exp }}$ and $T_{\mathrm{i}}^{\text {cal }}$ are, respectively, the experimental and calculated equilibrium temperatures at a given concentration $x_{1 i}$ and $A_{1}$ and $A_{2}$ are the two adjustable parameters of each correlation model.

The root mean square deviation of temperature was defined as:

$\sigma_{T}=\left[\sum_{\mathrm{i}=1}^{n} \frac{\left(T_{\mathrm{i}}^{\mathrm{exp}}-T_{\mathrm{i}}^{\mathrm{cal}}\right)^{2}}{\mathrm{n}-\mathrm{m}}\right]^{1 / 2}$

where $\mathrm{m}$ is the number of adjustable parameters which is equal to 2 in our case. The NRTL equation contains three parameters, but the reduction of experimental data for a large number of binary systems indicates that the non-randomness parameter $\alpha_{12}$ varies from about 0.20 to 0.47 . A typical choice is $\alpha_{12}=0.3[3,11,37]$, here adapted. Furthermore, the pure component structural parameters $r$ (volume parameter) and $q$ (surface parameter) in the UNIQUAC equations were calculated according to the procedure suggested by Hofman and Nagata [42].

The estimated parameters and corresponding root-mean-square deviations are summarized in Table 7. Fig. 4 provides a comparison between the experimental data and the correlation results as well as with the liquidus line assuming ideality. The three models calculate equilibrium temperatures satisfactorily with standard deviations for 

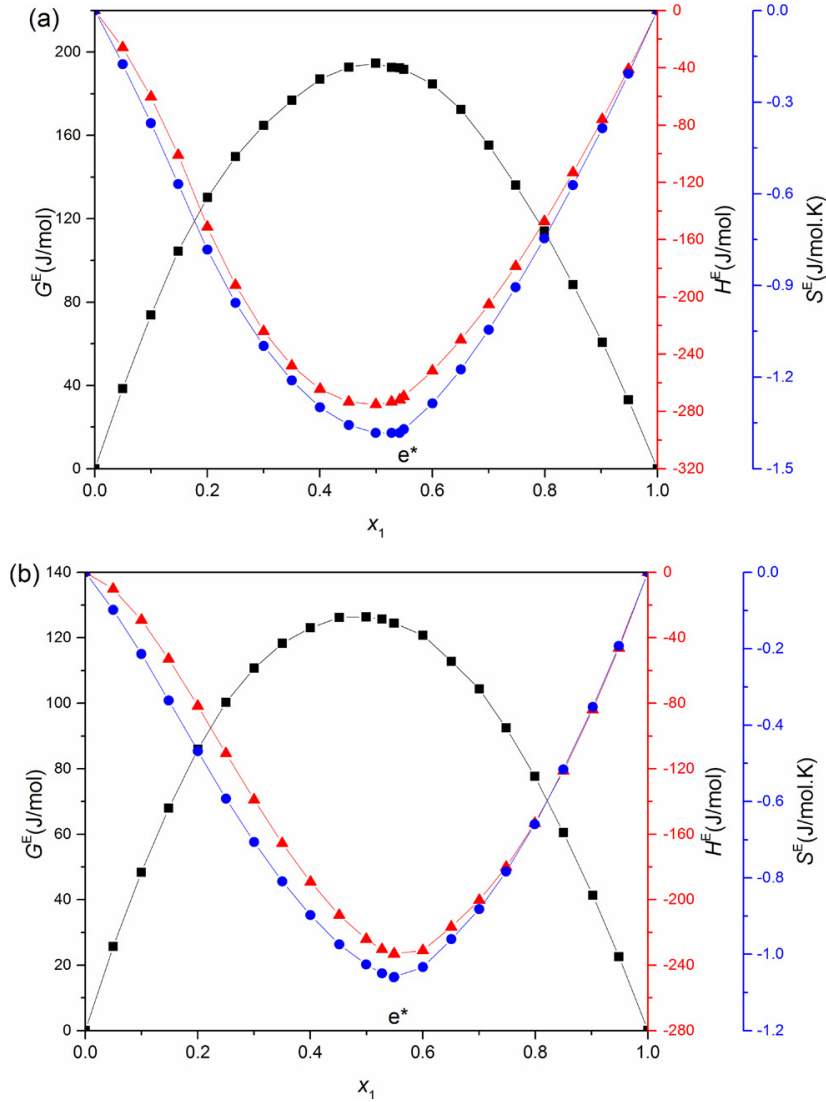

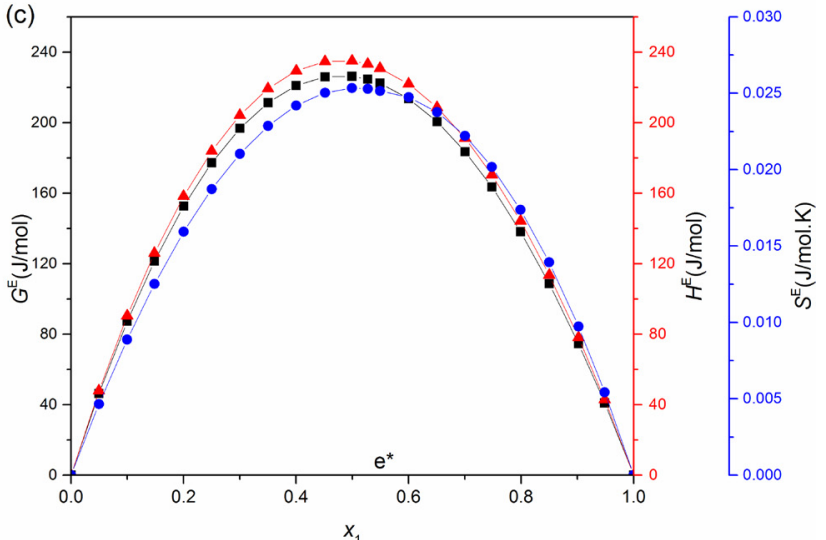


calculated eutectic).

NRTL and UNIQUAC, respectively, of $1.25 \mathrm{~K}$ and $1.36 \mathrm{~K}$ for the first system and of $2.23 \mathrm{~K}$ and $2.35 \mathrm{~K}$ for the second. Nevertheless, the Wilson model fitted the experimental data better than the two former ones with a root square mean deviation for S1 and S2 of $1.15 \mathrm{~K}$ and $1.99 \mathrm{~K}$ respectively.

As shown in Table 5, the deviation between the experimental and calculated values of $T_{\mathrm{E}}$ in the case of ideal solubility is more pronounced in the case of the second system. However, the eutectic coordinates calculated by the Wilson, NRTL and UNIQUAC equations are closer to the experimental values found based on the Tamman plot.

\subsubsection{Excess thermodynamic functions}

The excess thermodynamic functions, viz excess Gibbs enthalpy, enthalpy and entropy of the mixture are fundamental properties, which can provide a measure and type of the molecular interactions and the departure to ideal behavior.

The values of excess thermodynamic functions for systems S1 and S2 reported, respectively in Tables S1 and S2 of the supplementary materials are calculated using the temperature values obtained by the three models Wilson, NRTL, and UNIQUAC. Figs. 5 and 6 show these thermodynamic functions with respect to the mole fraction composition. All models give values highly comparable for a qualitative and quantitative analysis. Only the excess enthalpy and entropy calculated by UNIQUAC in system S1 present opposite trends to those calculated by the other two models and will, therefore, be excluded from the excess thermodynamic functions discussion.

Inversely to what has been found often in the literature [43-46], where mathematical extremes had been found for those properties exactly at the eutectic composition, in this study it is not possible to observe a global maximum or minimum of those properties at the eutectic point. Nevertheless, the excess values at these particular mole fractions are in general close to the recorded minima or maxima, which can be most probably attributed to a consequence of the minimum temperature value at the eutectic.

As a rule, the sign and magnitude of the enthalpy and Gibbs energy of excess reproduce differences in the intensity of intermolecular attractions between pairs of dissimilar species on one hand, and pairs of like species on the other [47-49]. Like shown in Fig. 4(a), system MENA(1) + NENA(2) presents a moderate positive deviation to ideality, both $G^{\mathrm{E}} / R T$ and $H^{\mathrm{E}} / R T$ (absolute values) are always smaller than 0.1, which is a result of a moderate self-association between the same pairs of the mixture components. Moreover, the application of the Wilson and NRTL model to S1 results in negative values of excess enthalpy and entropy while the excess Gibbs energy is positive meaning that the entropic effect is dominant.

Similarly, ENA(1) + NENA(2) mixture shows a strong positive deviation to ideality. Both $G^{\mathrm{E}} / R T$ and $H^{\mathrm{E}} / R T$ are positive, which is a typical behavior for mixtures of an associative and a nonpolar compound, which it is not the case, even if NENA is for sure less polar than ENA. This large positive deviation to ideality can be explained by the presence of $\mathrm{OH}$ group (ENA) and the dominant effect of hydrogen bonding between ENA molecules (self-association), which will be shown by FTIR analyses.

The structural contribution of the component fragment reproduces the sign and magnitude of excess entropy. Structure infringement involves a positive contribution to excess entropy and structure building a negative contribution to excess entropy [50]. From the negative values of the excess entropy obtained for both systems, it is likely that a structure building takes place owing to gathering forces which makes clustering within the solution.

\subsection{Microstructure studies of the eutectic mixtures}

The letters (a), (b), (c), (d) and (e) in Figs. 7 and 8, refer respectively 

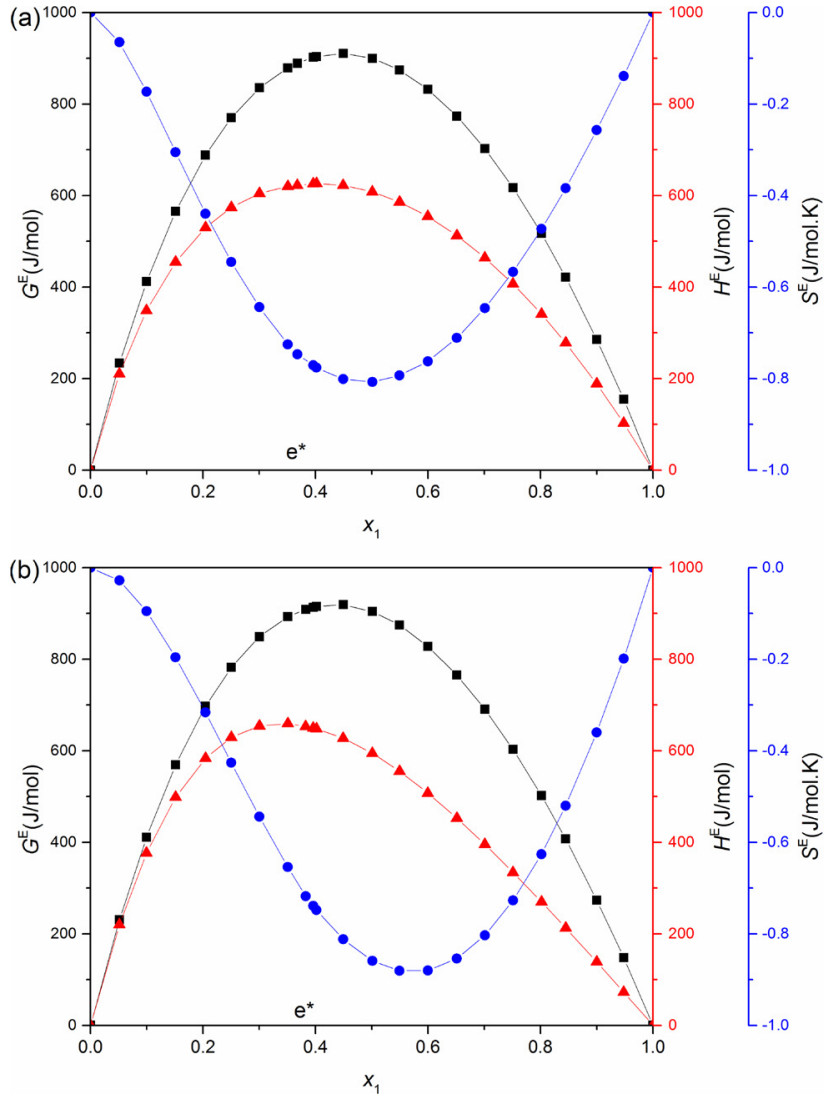

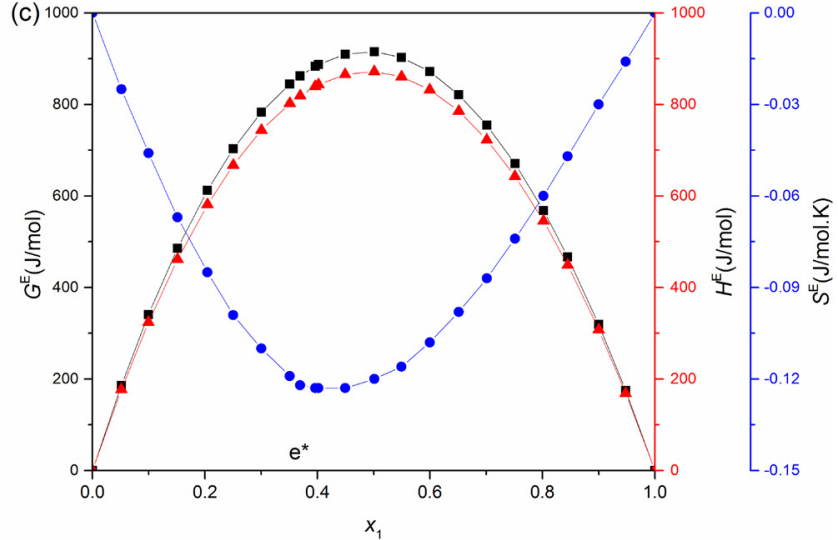


calculated eutectic).

to MENA, NENA, ENA, eutectic (MENA + NENA) and eutectic (ENA + NENA).

\subsubsection{Fourier transform infrared spectroscopy analysis (FTIR)}

FTIR studies are considered to provide information about molecular interactions between the mixture's components, especially at the eutectic composition. The FTIR spectra of pure components and the eutectic mixture under study are shown in plots (1) and (2) of Fig. 7. In general, hydrogen bonding to an X-H group results in a decrease in the $\mathrm{X}-\mathrm{H}$ stretching frequency accompanied by a broadening and intensification of this band [51,52]. Both $\mathrm{OH}$ and $\mathrm{NH}$ groups are found to exhibit highly characteristic changes with hydrogen bonding [52].

From FTIR spectrum of ENA (Fig.7(c)), it can be revealed that in the solid state the ENA molecules are associated with each other by an intermolecular hydrogen bond. The stretching frequency of H-bonded $-\mathrm{OH}$ group appears at $3440 \mathrm{~cm}^{-1}$ which is much lower than the stretching frequency of a non-hydrogen bonded $\mathrm{OH}$ group, generally observed at higher frequencies, from 3580 up to $3670 \mathrm{~cm}^{-1}$ [52,53], in particular when the molecular structure of the compound presents a steric hindrance [52] as is the case of ENA molecules. NH groups of the ENA have also involved hydrogen bonding since the NH stretching frequency $\left(3272 \mathrm{~cm}^{-1}\right)$ is relatively lower than that of free $\mathrm{NH}$ group generally observed at higher frequencies $\left(3300-3500 \mathrm{~cm}^{-1}\right)$ [52,53].

The FTIR spectrum of MENA (Fig. 7(a)) and NENA (Fig. 7(b)) shows the inexistence of an inter or intramolecular hydrogen bonding since the functional group capable of giving rise to such bonding $(\mathrm{NH})$ is observed as free group at FTIR stretching frequencies of $3341 \mathrm{~cm}^{-1}$ for MENA and $3347 \mathrm{~cm}^{-1}$ for NENA. The absence of such characteristic bands in those pure compounds reveals their inability to form intermolecular hydrogen bonding and predicts weak interactions between similar MENA and NENA molecules that can be broken easily.

We can clearly confirm that for the MENA + NENA system, the eutectic spectra (Fig. 7(d)) gather the totality of the characteristic frequencies of their respective pure components with no sensitive translation or shape modification of peaks, suggesting very weak molecular interaction between the two components in the eutectic mixture and supporting the moderate positive departure to ideality revealed by excess thermodynamic functions calculation.

The higher broadened frequency of the $\mathrm{H}$-bonded $-\mathrm{OH}$ group at the eutectic of the second mixture ENA + NENA (Fig. 7(e)) indicates weak interaction due to the polarity difference between the two mixture components. This promotes weak attractive forces between unlike molecules and reflects the dominant behavior of intermolecular hydrogen bonding in ENA, supporting the large positive trends obtained for the excess thermodynamic functions.

\subsection{2. $X$-ray diffraction analysis $(X R D)$}

The X-ray diffraction is used to highlight the crystal structure of the different compounds. Its application to the eutectic composition aims to study whether any possible change in the crystal structure occurs under molecular interaction effect.

The X-ray diagrams for the eutectic compositions of the two studied systems superposed with those of the pure components are presented in plots (1) and (2) of Fig. 8. The Bragg angles, the inter-reticular distances and the Miller indices of the eutectic mixture, as well as the pure compounds, were evaluated by the EXPO 2014 software [54].

It is obvious from Fig. 8(1) that MENA and NENA crystallize separately in their own crystals. In fact, the X-ray patterns of the first eutectic gather all the peaks of its pure compounds. Regarding the XRD data of the first eutectic and its respective pure components, it can be inferred that there is a difference in the interplanar distances (evaluated by Expo software) and the relative intensity suggesting thereby that the studied eutectic is a mechanical system [55] as it should be for a eutectic. The slight variation in the relative intensity of reflections of pure 

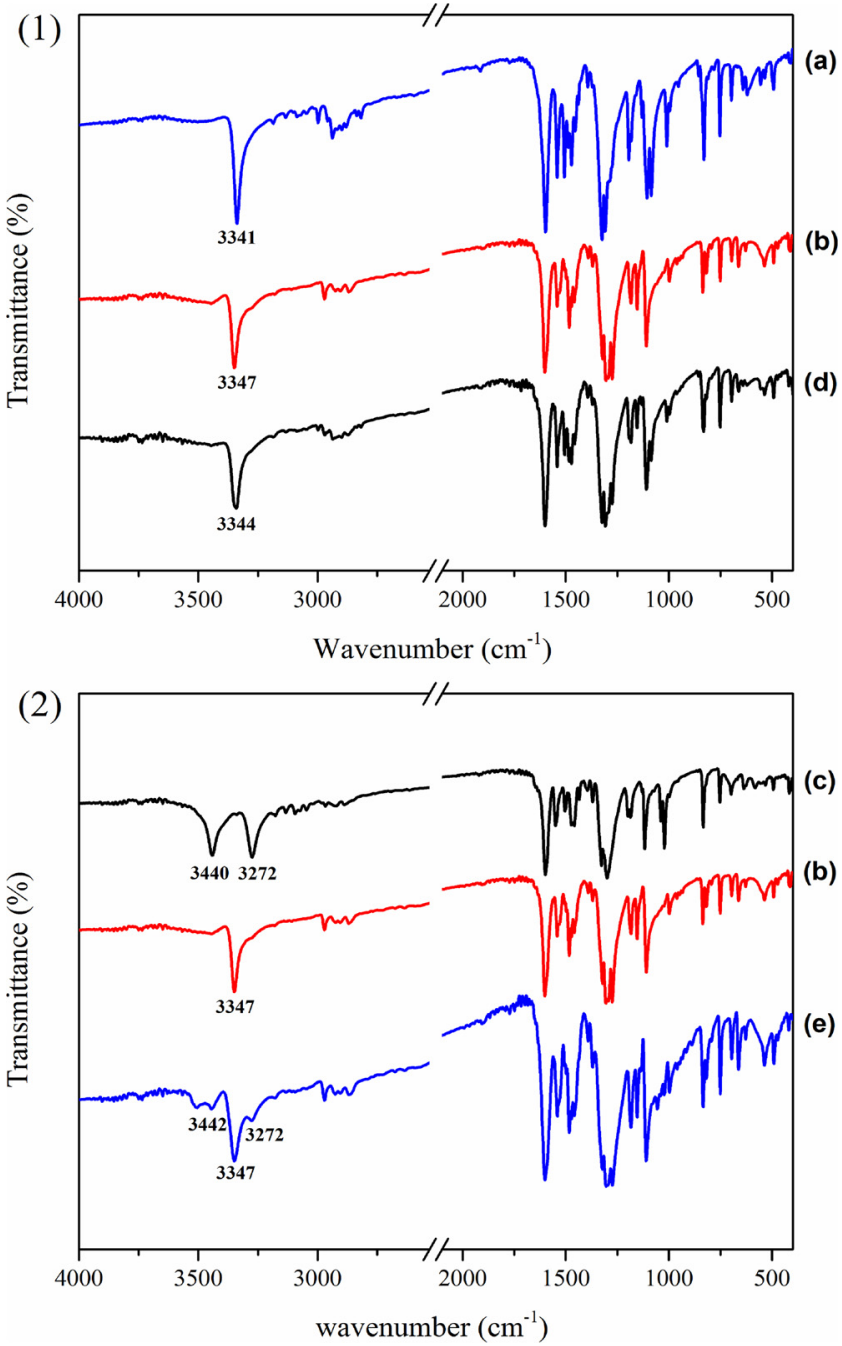

Fig. 7. FTIR Spectra of (1)S1; (2) S2 binary mixture: (a) pure MENA, (b) pure NENA, (c) pure ENA, (d) eutectic of (MENA + NENA) and (e) eutectic of (ENA + NENA) at $T=298.15 \mathrm{~K}$.

components in the first eutectic can be explained by the subsistence of weak molecular interactions between the components of the eutectic.

In the second eutectic (plot (2) of Fig. 8), we can clearly verify the absence of some peaks of the pure ENA and the presence of all those of NENA. In fact, the eutectic of the second system crystallizes in the same crystalline system as NENA. The absence of those of ENA in the eutectic should be explained by the development of a new phase corresponding to the formation of an intermediate solid below the eutectic, such as a peritectoid reaction.

\subsubsection{Optical microscopy microstructure characterization}

Microstructure studies are another important feature, which helps to understand the crystallization behavior of the materials and to know more about the disposition of the pure compound grains and eventual modifications undergone during the formation of the eutectics. The microstructures of pure components and the eutectic compositions are shown in Fig. 9. The microstructure of pure MENA (a) and ENA (c) shows lamellar type structure. It is evident that pure NENA (b) exhibits an irregular structure. The eutectic of the first system (d) shows triangular shaped crystals arranged in an irregular fashion, whereas that of the second (e) displays an irregular microstructure.

The microstructures and facet size are influenced by various factors such as steady state diffusion, interfacial contact angle, kinetic equilibrium characteristics, growth rate, composition, ease of nucleation of
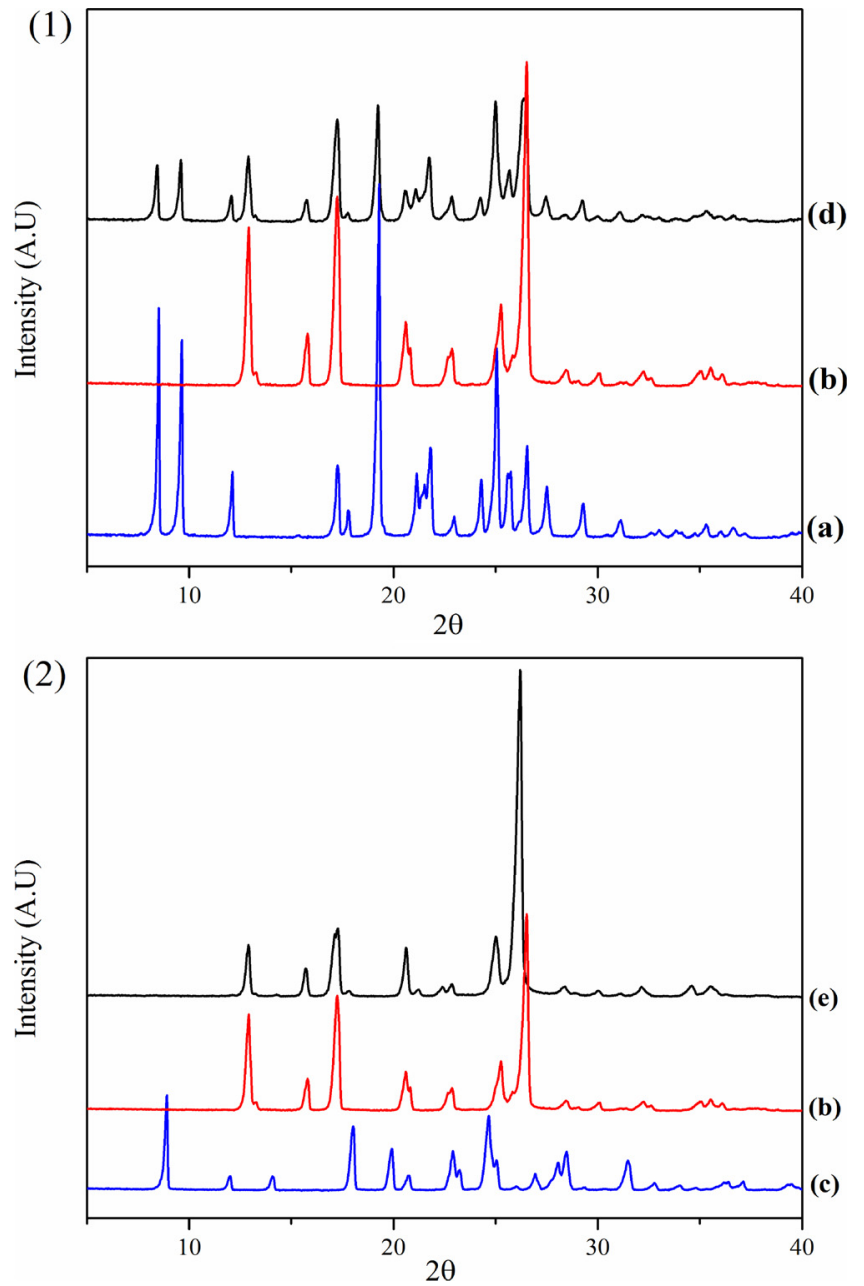

Fig. 8. X-ray diffractograms of (1) S1; (2) S2 binary mixture:(a) pure MENA, (b) pure NENA, (c) pure ENA, (d) eutectic of (MENA + NENA) and (e) eutectic of (ENA + NENA) at $T=298.15 \mathrm{~K}$.

faceted phase, etc [43]. It also depends on the number of defects viz. voids, growth twins, dislocations, etc. However, the microstructure of the eutectic mixtures could be predicted from the values of the melting entropy. According to Hunt and Jackson, the type of growth from a binary melt can be predicted on the basis of roughness parameter $\alpha$, defined as follows [56]:

$\alpha=\xi \Delta S_{\mathrm{E}} /_{R}=\xi \Delta H_{\mathrm{E}} / R T_{\mathrm{E}}$

where $\xi$ is a geometrical coefficient often called as the crystallographic factor, depending upon the geometry of the molecules and has a value less than or equal to $1, \Delta H_{\mathrm{E}}$ and $T_{\mathrm{E}}$ correspond to the experimental eutectic melting properties. The values of $\alpha$ (Table 8) were calculated by substituting the $\xi$ value by 0.5 and 1 . It is reported that when the roughness parameter $\alpha$ is greater than 2, solidus-liquidus interfacial growth takes place with faceted morphology [56]. The values of $\alpha$ for the two eutectics are found to be greater than 2, thus they possessed faceted morphology with irregular structures. The surface obtained is rather smooth and the crystal develops with morphology side by side, with no interstices.

\section{Conclusions}

In this work, (solid + liquid) phase equilibria for two binary mixtures of energetic material's stabilizers have been studied in order to predict their evolution and to see their thermodynamic behavior with 

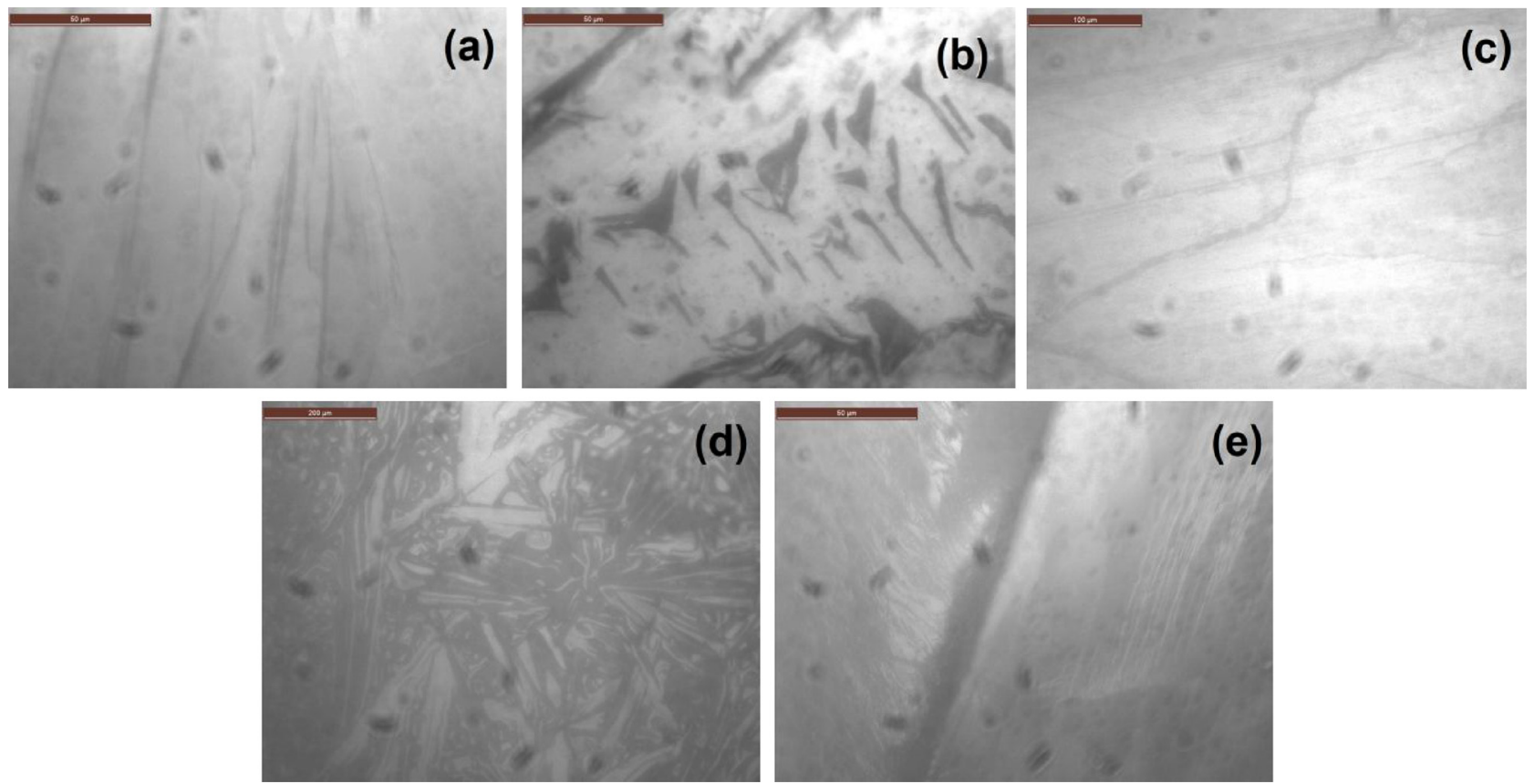

Fig. 9. Optical microscope microstructure at $50 \times$ magnification and at $T=298.15$, (a) MENA, (b) NENA, (c) ENA, (d) eutectic of MENA + NENA, (e) eutectic of ENA + NENA.

Table 8

Roughness factors for the eutectics: $\Delta H_{\mathrm{E}}, \alpha, \xi$ denote the eutectic melting enthalpy, the roughness parameter, and the crystallographic factor, respectively.

\begin{tabular}{llll}
\hline \multirow{2}{*}{ System } & $\Delta H_{\mathrm{E}, \exp }(\mathrm{kJ} / \mathrm{mol})$ & $\alpha$ & \\
\cline { 3 - 4 } & & $\xi=0.5$ & $\xi=1.0$ \\
\hline MENA + NENA & $22.3^{\mathrm{a}}$ & 4.00 & 8.00 \\
ENA + NENA & $16.3^{\mathrm{a}}$ & 2.77 & 5.54 \\
\hline
\end{tabular}

${ }^{\text {a }}$ Calculated eutectic enthalpy of melting uncertainty $u$ is $u\left(\Delta H_{\mathrm{E}, \mathrm{cal}}\right)$ $= \pm 0.7 \mathrm{~kJ} / \mathrm{mol}$.

respect to temperature changes. Obviously, the DSC technique is fairly satisfactory for the measurement of SLE, with very satisfactory consistency quality factors. All the investigated systems are simple eutectic. The data concerning the SLE, principally the eutectic composition of the studied systems is of great importance in the stability evaluation of energetic materials. The obtained results demonstrate that it is imperative, prior to any introduction of stabilizer mixtures in an energetic material formulation, to check, the temperature of the eutectic point because if the latter is close to the ambient one, more particularly, in the hot regions, a loss of the stability will be recorded leading to undesired phenomena.

The Wilson, NRTL and UNIQUAC models are capable of correlating accurately the binary SLE data and represent very satisfactorily the solid-liquid phase diagrams for the binary systems. Inversely to what has been found often in the literature, excess properties at the eutectic composition do not present a minimum or maximum.

Microstructural studies have shown weak molecular interaction between the two components in the two eutectic mixtures. Also, the eutectics display irregular microstructure and has been confirmed by the calculation of their roughness parameters.

This study will certainly contribute to a good understanding of the mixtures behavior of stabilizers and will be of great utility in the choice of storage conditions for ammunition. The results obtained will undoubtedly provide valuable information on the SLE of the stabilizers used in propellant grains and NC-based gun-powders. Thermodynamic and microstructural investigations carried out in this work allowed to verify that the eutectic compositions of binary mixtures of organic stabilizers can be introduced into the formulations of propellant based nitrate esters.

\section{Acknowledgments}

The authors are grateful for the financial support of this research from Ecole Militaire Polytechnique (Doctoral Training Program) and from Associate Laboratory LSRE-LCM, Instituto Politécnico de Bragança (projectPOCI-01-0145-FEDER-006984) funded by European Regional Development Fund (ERDF) through COMPETE2020 -Programa Operacional Competitividade e Internacionalização (POCI) - and by national funds through FCT - Fundaçãopara a Ciência e a Tecnologia. C.M.S.S. Neves thanks FCT for the postdoctoral grant SFRH/BPD/ $109057 / 2015$.

\section{Appendix A. Supplementary data}

Supplementary material related to this article can be found, in the online version, at doi:https://doi.org/10.1016/j.tca.2018.07.002.

\section{References}

[1] D. Trache, A.F. Tarchoun, Stabilizers for nitrate ester-based energetic materials and their mechanism of action: a state-of-the-art review, J. Mater. Sci. 53 (2018) $100-123$.

[2] S. Wilker, G. Heeb, B. Vogelsanger, J. Petržílek, J. Skládal, Triphenylamine-a 'New'stabilizer for nitrocellulose based propellants-part I: chemical stability studies, Propellants Explos. Pyrotech. 32 (2007) 135-148.

[3] D. Trache, K. Khimeche, Study on the influence of ageing on thermal decomposition of double-base propellants and prediction of their in-use time, Fire Mater. 37 (2013) 328-336.

[4] D. Trache, K. Khimeche, A. Mezroua, M. Benziane, Physicochemical properties of microcrystalline nitrocellulose from Alfa grass fibres and its thermal stability, J. Therm. Anal. Calorim. 124 (2016) 1485-1496.

[5] M.A. Bohn, NC-based energetic materials-stability, decomposition and ageing, Nitrocellulose-Supply, Ageing and Characterization Meeting, (2007), pp. 24-25.

[6] D. Trache, K. Khimeche, Study on the influence of ageing on chemical and mechanical properties of $N, N^{\prime}$-dimethyl- $N, N^{\prime}$-diphenylcarbamide stabilized propellants, J. Therm. Anal. Calorim. 111 (2013) 305-312.

[7] M.N. Boers, W.W.P. de Klerk, Lifetime prediction of EC, DPA, akardite II and MNA stabilized triple base propellants, comparison of heat generation rate and stabilizer consumption, Propellants Explos. Pyrotech. 30 (2005) 356-362. 
[8] M.A. Bohn, F. Volk, Aging behavior of propellants investigated by heat generation, stabilizer consumption, and molar mass degradation, Propellants Explos. Pyrotech. 17 (1992) 171-178.

[9] M. Zayed, A.A. Mohamed, M. Hassan, Stability studies of double-base propellants with centralite and malonanilide stabilizers using $\mathrm{MO}$ calculations in comparison to thermal studies, J. Hazard. Mater. 179 (2010) 453-461.

[10] D. Trache, K. Khimeche, A. Dahmani, Study of (solid-liquid) phase equilibria for mixtures of energetic material stabilizers and prediction for their subsequent performance, Int. J. Thermophys. 34 (2013) 226-239.

[11] D. Trache, K. Khimeche, R. Benelmir, A. Dahmani, DSC measurement and prediction of phase diagrams for binary mixtures of energetic materials' stabilizers, Thermochim Acta 565 (2013) 8-16.

[12] A. Mekki, K. Khimeche, A. Dahmani, Measurement and prediction of (solid + liquid) equilibria of gun powder's and propellant's stabilizers mixtures, J. Chem. Thermodyn. 42 (2010) 1050-1055.

[13] J.D. Gibson, Stabilizers for cross-linked composite modified double base propellants, in, US Patent 5,387,295, 1995.

[14] F. Zou, W. Zhuang, J. Wu, J. Zhou, Q. Liu, Y. Chen, J. Xie, C. Zhu, T. Guo, H. Ying, Experimental measurement and modelling of solubility of inosine-5'-monophosphate disodium in pure and mixed solvents, J. Chem. Thermodyn. 77 (2014) $14-22$.

[15] J. Xu, Y. Wang, G. Wang, C. Huang, H. Hao, Q. Yin, Thermodynamic equilibrium of 4-hydroxy-2, 5-dimethyl-3 (2H)-furanone in different solvent systems, J. Chem. Thermodyn. 92 (2016) 12-20.

[16] G. Ma, L. Han, J. Sun, Y. Jia, Thermal properties and reliability of eutectic mixture of stearic acid-acetamide as phase change material for latent heat storage, J. Chem. Thermodyn. 106 (2017) 178-186.

[17] D. Cabaleiro, C. Gracia-Fernandez, L. Lugo, (Solid + liquid) phase equilibria and heat capacity of (diphenyl ether + biphenyl) mixtures used as thermal energy storage materials, J. Chem. Thermodyn. 74 (2014) 43-50.

[18] G. Ma, J. Sun, Y. Jia, S. Xie, Z. Wang, Y. Jing, Solid-liquid phase equilibria of stearic acid and dicarboxylic acids binary mixtures as low temperature thermal energy storage materials, J. Chem. Thermodyn. (2018).

[19] Y. Corvis, A. Spasojević-de Biré, C. Alzina, N. Guiblin, P. Espeau, Kinetics of the (solid + solid) transformations for the piracetam trimorphic system: incidence on the construction of the $\mathrm{p}-\mathrm{T}$ equilibrium phase diagram, J. Chem. Thermodyn. 97 (2016) 167-172.

[20] L.P.S. Silva, D. Dalmazzone, M. Stambouli, A.-L. Lesort, P. Arpentinier, A. Trueba, W. Fürst, Phase equilibria of semi-clathrate hydrates of tetra-n-butyl phosphonium bromide at atmospheric pressure and in presence of $\mathrm{CH} 4$ and $\mathrm{CO} 2+\mathrm{CH} 4$, Fluid Phase Equilib. 413 (2016) 28-35.

[21] J.H. Oakley, T.J. Hughes, B.F. Graham, K.N. Marsh, E.F. May, Determination of melting temperatures in hydrocarbon mixtures by differential scanning calorimetry, J. Chem. Thermodyn. 108 (2017) 59-70.

[22] M.C. Costa, M.P. Rolemberg, L.A. Boros, M.A. Krähenbühl, M.G. de Oliveira, A.J. Meirelles, Solid - liquid equilibrium of binary fatty acid mixtures, J. Chem. Eng. Data 52 (2007) 30-36.

[23] D.-C. Marinescu, E. Pincu, I. Stanculescu, V. Meltzer, Thermal and spectral characterization of a binary mixture (acyclovir and fluocinolone acetonide): eutectic reaction and inclusion complexes with $\beta$-cyclodextrin, Thermochim Acta 560 (2013) 104-111.

[24] T. Kousksou, A. Jamil, T. El Rhafiki, Y. Zeraouli, Paraffin wax mixtures as phase change materials, Sol. Energy Mater. Sol. Cells 94 (2010) 2158-2165.

[25] H. Takiyama, H. Suzuki, H. Uchida, M. Matsuoka, Determination of solid-liquid phase equilibria by using measured DSC curves, Fluid Phase Equilib. 194 (2002) 1107-1117.

[26] C.-C. Huang, Y.-P. Chen, Measurements and model prediction of the solid-liquid equilibria of organic binary mixtures, Chem. Eng. Sci. 55 (2000) 3175-3185.

[27] I. Paunovic, A.K. Mehrotra, Liquid-solid phase transformation of C16H34, C28H58 and C41H84 and their binary and ternary mixtures, Thermochim Acta 356 (2000) 27-38.

28] A. Hammami, A.K. Mehrotra, Liquid-solid-solid thermal behaviour of n-C44H90 + n-C50H102 and n-C25H52 + n-C28H58 paraffinic binary mixtures, Fluid Phase Equilib. 111 (1995) 253-272.

[29] N.J. Curtis, Technical report, WSRL-0563-TR, Weapons systems research laboratory, (1987) Salisbury, South Australia.

[30] M.H. Keshavarz, A.R. Akbarzadeh, R. Rahimi, M. Jafari, M. Pasandideh, R. Sadeghi, A reliable method for prediction of enthalpy of fusion in energetic materials using their molecular structures, Fluid Phase Equilib. 427 (2016) 46-55.

[31] A. Jain, G. Yang, S.H. Yalkowsky, Estimation of melting points of organic compounds, Ind. Eng. Chem. Res. 43 (2004) 7618-7621.

[32] E. Baum, Chemical Property Estimation: Theory and Application, CRC Press, 1997.

[33] H. Gamsjäger, J.W. Lorimer, P. Scharlin, D.G. Shaw, Glossary of terms related to solubility (IUPAC Recommendations 2008), Pure Appl. Chem. 80 (2008) 233-276.

[34] E.V. Agafonova, Y.V. Moshchenskiy, M.L. Tkachenko, DSC study and calculation of metronidazole and clarithromycin thermodynamic melting parameters for individual substances and for eutectic mixture, Thermochim Acta 580 (2014) 1-6.

[35] J.W. Kang, V. Diky, R.D. Chirico, J.W. Magee, C.D. Muzny, A.F. Kazakov, K. Kroenlein, M. Frenkel, Algorithmic framework for quality assessment of phase equilibrium data, J. Chem. Eng. Data 59 (2014) 2283-2293.

[36] U. Domańska, J. Łachwa, Thermodynamics of binary mixtures of N-methyl-2-pyrrolidinone and ketone. Experimental results and modelling of the (solid + liquid) equilibrium and the (vapour + liquid) equilibrium. The modified UNIFAC (Do) model characterization, J. Chem. Thermodyn. 37 (2005) 692-704.

[37] J.M. Prausnitz, R.N. Lichtenthaler, E.G. de Azevedo, Molecular Thermodynamics of Fluid-Phase Equilibria, Pearson Education, 1998.

[38] R. Reddi, V.K. Satuluri, U. Rai, R. Rai, Thermal, physicochemical and microstructural studies of binary organic eutectic systems, J. Therm. Anal. Calorim. 107 (2012) 377-385.

[39] R. Reddi, V. Kumar Satuluri, R. Rai, Solid-liquid equilibrium, thermal and physicochemical studies of organic eutectics, J. Therm. Anal. Calorim. 107 (2011) 183-188.

[40] A. Iddaoudi, N. Selhaoui, M.A. Amar, K. Mahdouk, A. Aharoune, L. Bouirden, Thermodynamic description of the Lu-Pb binary system, J. Therm. Anal. Calorim. 110 (2012) 923-928.

[41] J.A. Nelder, R. Mead, A simplex method for function minimization, Comput. J. 7 (1965) 308-313.

[42] T. Hofman, I. Nagata, Determination of association constants for alcohols based on ethers as homomorphs, Fluid Phase Equilib. 25 (1986) 113-128.

[43] P. Gupta, T. Agrawal, S.S. Das, N.B. Singh, Phase equilibria and molecular interaction studies on (naphthols + vanillin) systems, J. Chem. Thermodyn. 48 (2012) 291-299.

[44] B. Sharma, N. Sharma, M. Rambal, Excess thermodynamic functions: GE and SE of binary organic eutectic systems, Thermochim Acta 206 (1992) 71-84.

[45] B. Sharma, R. Kant, R. Sharma, S. Tandon, Deviations of binary organic eutectic melt systems, Mater. Chem. Phys. 82 (2003) 216-224.

[46] B. Sharma, S. Gupta, S. Tandon, R. Kant, Physico-mechanical properties of naphthalene-acenaphthene eutectic system by different modes of solidification, Mater. Chem. Phys. 111 (2008) 423-430.

[47] S.E. Hamam, G.C. Benson, M. Kumaran, Excess enthalpies of (water + diethylene glycol) and (water + triethylene glycol), J. Chem. Thermodyn. 17 (1985) 973-976.

[48] M. Okuniewski, K. Paduszyński, U. Domańska, (Solid + liquid) equilibrium phase diagrams in binary mixtures containing terpenes: New experimental data and analysis of several modelling strategies with modified UNIFAC (Dortmund) and PCSAFT equation of state, Fluid Phase Equilib. 422 (2016) 66-77.

[49] U. Rai, P. Pandey, Solidification and thermal behaviour of binary organic eutectic and monotectic; succinonitrile-pyrene system, J. Cryst. Growth 249 (2003) 301-308.

[50] S.M. Nayeem, Investigation of molecular interactions \& prediction of calorimetric potentials of a binary liquid system at $\mathrm{T}=308.15 \mathrm{~K}$ : an insight from physicochemical parameters, Karbala Int. J. Mod. Sci. (2017).

[51] S.V. Latha, G.L. Flower, K.R. Reddy, C.N. Rao, A. Ratnakar, Densities, ultrasonic velocities, excess properties and IR spectra of binary liquid mixtures of organic esters (ethyl lactate, some organic carbonates), J. Solut. Chem. 46 (2017) 305-330.

[52] P. Larkin, Infrared and Raman Spectroscopy: Principles and Spectral Interpretation, Elsevier, 2011.

[53] G. Socrates, Infrared and Raman Characteristic Group Frequencies: Tables and Charts, John Wiley \& Sons, 2004.

[54] A. Altomare, N. Corriero, C. Cuocci, A. Falcicchio, A. Moliterni, R. Rizzi, EXPO software for solving crystal structures by powder diffraction data: methods and application, Cryst. Res. Technol. 50 (2015) 737-742.

[55] U. Rai, M. Singh, R. Rai, Some physicochemical studies on organic eutectics and inter-molecular compounds, J. Therm. Anal. Calorim. 130 (2017) 967-974.

[56] J. Hunt, K. Jackson, Binary eutectic solidification, Trans. Metall. Soc. AIME 236 (1966) 843. 